\title{
Dear colleague, please, do not ask for ultrasound studies for inguinal hernia diagnosis
}

\author{
C. Brandi
}

Received: 7 December 2014/ Accepted: 19 December 2014/Published online: 6 January 2015

(C) Springer-Verlag France 2014

\section{Dear Colleague,}

This is an appeal to your good will. Would you be so kind as not to ask for ultrasound studies for inguinal hernia diagnosis, please? Hernias constitute a pathology that can be seen and palpated.

Groin hernias represent a highly prevalent pathology which can, therefore, consume many resources [1].

Hernia diagnosis has been always based on the presence of pain and on hernia sac palpation. Observation and palpation of hernia tumoration represent sine qua non conditions for surgery. The sole presence of pain, burning or discomfort does not confirm the presence of a hernia and, therefore, the patient must not be operated on.

Nowadays, when patients come for consultation, they complain of inguinal pain and bring an ultrasound study reporting: "a hernia sac of very few mm". The patient generally says: "I have come to see you because I have a hernia and I need to be operated on. I have had inguinal pain for 2 weeks. My primary care physician asked for an ultrasound study which revealed a 5-mm inguinal hernia". Thus, a problem comes up when we, surgeons, do not palpate the hernia and we inform the patient that he should not be operated on [2]. Therefore, an issue difficult to explain arises at this point.

The patient then asks: "Why don't you want to operate on me if I feel pain and I have an ultrasound study reporting a hernia? Is the ultrasound study useless? Why did they ask for it then? What do I really have?"

The fact that nowadays patients trust more the content of the ultrasound report than what the surgeon tells them is worth mentioning. However, when they are told that we cannot perform an operation based solely on the ultrasound study since we run the risk of carrying out the procedure and of not finding the hernia, patients understand the situation more clearly.

In fact, we, experienced surgeons, do not request complementary studies for hernia diagnosis. We see our patients in different visits, palpate the area very well and control the patient's evolution. If the pain is caused by a hernia in the early stage, the hernia will clearly manifest itself in very few weeks. Otherwise, the pain can be just muscular or tendinous and can be resolved either spontaneously or with anti-inflammatory drugs.

In conclusion, I believe that the most efficient strategy consists in listening to the patient, examining him thoroughly and referring him to the surgeon for the professional to confirm the diagnosis. Thus, we will save resources and avoid misunderstandings.

Conflict of interest $\mathrm{CB}$ declares no conflict of interest.

\section{References}

1. Alabraba E, Psarelli E, Meakin K et al (2014) The role of ultrasound in the management of patients with occult groin hernias. Int J Surg 12(9):918-922

2. Miller J, Cho J, Michael MJ et al (2014) Role of imaging in the diagnosis of occult hernias. JAMA Surg 20:484
C. Brandi $(\bowtie)$

Hospital Italiano de Buenos Aires, Buenos Aires, Argentina

e-mail: claudio.brandi@hospitalitaliano.org.ar 